\title{
Sugar and artificially sweetened beverage consumption and adiposity changes: National longitudinal study
}

\author{
Anthony A Laverty ${ }^{1 *}$, Lucia Magee ${ }^{1}$, Carlos A. Monteiro², Sonia Saxena ${ }^{1}$ and Christopher Millett ${ }^{1}$
}

\begin{abstract}
Background: In response to increasing policy action and public concern about the negative health effects of sugar-sweetened beverages (SSBs), there is increased promotion of artificially sweetened beverages (ASBs). These have been linked with obesity and diabetes in recent experimental work. This study examined associations between SSB and ASB consumption and changes in adiposity in a nationally representative sample of UK children.

Methods: We conducted a longitudinal study of 13,170 children aged 7-11 years in the UK Millennium Cohort Study, collected in 2008 and 2012. Logistic regression was used to assess socio-demographic and behavioural correlates of weekly SSB and ASB consumption at 11 years. Linear regression examined associations between SSB/ASB consumption and changes in adiposity measures between 7 and 11 years.

Results: Boys were more likely to consume SSBs weekly (62.3 \% v $59.1 \%$ ) than girls at age 11 years. South Asian children

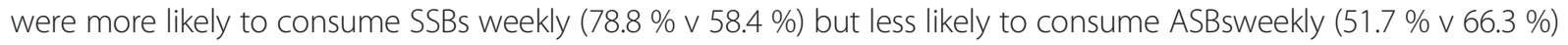
than White children. Daily SSB consumption was associated with increases in percentage body fat between ages 7 and 11 ( $+0.57 \%, 95 \%$ confidence intervals 0.30;0.83). Daily ASB consumption was associated with increased percentage body fat at age $11\left(+1.18 \mathrm{~kg} / \mathrm{m}^{2}, 0.81 ; 1.54\right)$ and greater increases between ages 7 and $11\left(+0.35 \mathrm{~kg} / \mathrm{m}^{2}, 0.09 ; 0.61\right)$.

Conclusion: Consumption of SSBS and ASBs was associated with BMI and percentage body fat increases in UK children. Obesity prevention strategies which encourage the substitution of SSBs with ASBs may not yield the adiposity benefits originally intended and this area should be a focus for further research.
\end{abstract}

\section{Background}

Sugar sweetened beverage (SSB) consumption is an established risk factor for overweight and obesity and type 2 diabetes [1]. A meta-analysis of available longitudinal data indicates that children consuming one SSB each day are $55 \%$ more likely to be overweight compared to those with limited consumption [1]. A cross-national study of 75 countries found that a $1 \%$ increase in soft drink consumption is associated with an additional 4.8 cases of overweight and 2.3 cases of obesity per 100 adults [2]. Findings from a meta-analysis of prospective cohort studies found that individuals consuming 1-2 servings of SSB

\footnotetext{
* Correspondence: a.laverty@imperial.ac.uk

'Department of Primary Care and Public Health, School of Public Health, Imperial College London, Reynolds Building, St Dunstan's Road, London W6 8RP, United Kingdom

Full list of author information is available at the end of the article
}

each day had a $26 \%$ greater risk of developing type 2 diabetes than those with no or very low consumption [3].

Although policy responses to this evidence remains limited, restriction of marketing and promotion of SSBs to children, reducing access to SSBs at school and taxation increases have been instituted in some jurisdictions [4-6]. While these interventions appear to show promise in reducing SSB consumption, they may induce substitution to lower calorie, artificially sweetened beverage (ASB) products. ASBs are increasingly being marketed by the soft drinks industry in response to increasing scope for regulation and declining consumer preferences for SSBs in some settings [7, 8].

Positive associations between use of artificial sweeteners and markers of obesity and diabetes have been identified in recent experimental work in mice and humans [9]. A limited number of small observational studies examining associations between ASB consumption and adiposity in 
children have produced mixed findings and none have used nationally representative, longitudinal data $[10,11]$. This study has two objectives:- (1) to document the prevalence and correlates of SSB and ASB consumption at age 11 years and; (2) examine associations of SSB/ASB consumption with adiposity at age 11 and with changes in adiposity between 7 and 11 years in a large nationally representative sample of UK children.

\section{Methods}

\section{Sample and data}

The Millennium Cohort Study (MCS) is a longitudinal national birth cohort study of children born in the United Kingdom (UK) between September 2000 and January 2002, alive and living in the UK at age 9 months, and eligible to receive child benefit [12]. Children were sampled using a stratified cluster sampling framework. Smaller population groups were over-sampled for the survey, including children living in disadvantaged areas, those from ethnic minority backgrounds and those living in the smaller nations of the UK. Interviews with caregivers were conducted when children were aged nine months and follow up data is currently available for four additional survey waves when children were aged 3, 5, 7 and 11 years. The survey covers a wide range of topics related to the social, economic and health circumstances of children in the UK. Full details of the study are published elsewhere [13]. Administration of questionnaires and direct measurements are carried out at home by trained interviewers using standardized protocols.

This study uses data from waves 4 and 5 of the MCS when children in the cohort are aged 7 and 11 years, collected in 2008 and 2012. The wave 5 sample consisted of 13,287 main cohort children. We excluded 117 children who were missing data for SSB and ASB consumption leaving a sample of 13,170 children. Data was analysed in 2015.

\section{Variables}

Our main exposure variable was caregiver reporting of consumption of SSBs and ASBs at age 11 years. This was based on answers to the questions: (1) How often, if at all, does [name] drink sweetened drinks e.g. cola, squash or Sunny Delight? and (2) How often, if at all, does [name] drink artificially sweetened drinks e.g. diet cola, sugar-free squash? There were seven possible answers to the question ranging from "never" to "more than once a day". Exposure was categorised into three groups of never/less than once a week; one to six times a week (weekly); and at least once a day (daily). This was in order to assess possible dose-response in any relationships between consumption and adiposity, and also this grouping provided adequate numbers in each group to ensure stability of estimates.
No specific questions on ASB or SSB consumption were asked in the age 7 surveys and so analyses utilising change in beverage consumption were not possible. Our continuous outcome measures were Body Mass Index (BMI) and percentage body fat objectively measured by trained interviewers. Height was measured using a Leicester stadiometer to the nearest millimetre, while weight and percentage body fat were measured using Tanita BF-522 W scales.

Other data was also based on caregiver reporting, and we attempted to control for a variety of factors which have been associated with adiposity among children in other work, including socio-demographics, dietary behaviours and physical activity [14-16]. Specifically, covariates included in fully-adjusted models were: age (in months), sex, ethnic group (White, South Asian, Black,), equivalised household income (based on the Organisation for Economic Co-operation and Development and categorised as those above and below $60 \%$ of median income as a marker of poverty [17]), mother's highest educational qualification (no formal qualifications, GCSE (usually completed at 16 years), A-levels (usually completed at 18 years), university or equivalent), country (England, Wales, Scotland, Northern Ireland), portions of fruit consumed per day ( $<3$ vs. $\geq 3$ pieces per day), breakfast consumption (seven days per week vs. not), days per week of sport/exercise (< once a week, 1-2 times a week, 3+ times a week), hours spent watching TV per weekday $(<2 \mathrm{~h}$ vs. $\geq 2 \mathrm{~h})$ and mode of transport to school (walk, cycle, public transport vs. car). No other dietary data was available from the age $11 \mathrm{MCS}$ data although we additionally controlled for snacking behaviour between meals at age 7 (from none to all three of "cakes and sweet biscuits", "crisps and other similar snacks" and "sweets or other chocolate") and being on a controlled diet to lose weight at age 7 (answers of "to lose or control weight" to the question "During the past 12 months have you controlled the type or amount [name] eats or drinks for any of these reasons).

\section{Statistical analysis}

Descriptive statistics were used to examine the distribution of exposure, outcomes and socio-demographic factors. Logistic regression was used to assess correlates of sweetened beverage consumption at least once a week (SSBs and ASBs considered separately) at age 11 years. Associations between categorical sweetened beverage consumption and BMI and percentage body fat at age 11 years were examined in cross-sectional analyses using linear regression. Adiposity at age 7 was then fitted in models to examine associations between sweetened beverage consumption and changes in adiposity between ages 7 and 11 years. Survey weights provided for the 
Millennium Cohort Study were used to correct for sampling, attrition between waves and non-response and to ensure national representativeness of anlayses [13]. These survey weights are constructed by the MCS survey team for each wave of the survey and are based on a logistic model of non-response, based on (among others) sex, mother's age at first birth, housing tenure, ethnicity and caregiver work status [18].We performed various sensitivity analyses to assess the robustness of our results. We repeated BMI analyses using BMI-Z scores as the outcome (constructed from standard reference equations [19]). We adjusted for height and height squared in models with body fat as the outcome measure, as previous work indicates there may be a quadratic association between body fat mass and height [20, 21]. Exposure to ASBs and SSBs was not mutually exclusive in the sample as a large number of children (40.7 \%) were consuming both. We therefore conducted analyses using the following four way categorization of weekly consumption (due to sample size constraints): consuming neither (16.4 \% of sample); consuming ASB but not SSB at least once a week (22.8 \% of sample); consuming SSB but not ASB at least once a week $(20.0 \%$ of sample); consuming both ASB and SSB at least weekly ( $40.8 \%$ of sample). Finally we performed analyses excluding children who were obese (classified either by BMI-Z score as obese or in the top $5 \%$ of the distribution of percentage body fat [22]) in order to examine possible reverse causality whereby obese children moved towards ASBs. All analyses were conducted in Stata v12.1.

As this study involved secondary analysis the MCS ethical approval was not required. Data collection for the MCS has ethical approval from the Yorkshire and Humber ethics committee and further details are available from http://www.cls.ioe.ac.uk/.

\section{Results}

The sample of 13,170 children was $49.5 \%$ female (Table 1) $82.9 \%$ white, $9.6 \%$ South Asian and $3.2 \%$ Black. Most of the sample lived in England (64.8\%) with the fewest living in Northern Ireland (9.9 \%). Three or more portions of fruit per day were eaten by $41.7 \%$ and $86.6 \%$ reported eating breakfast seven days per week. Partaking in sport or exercise on three or more days per week was reported by $32.1 \%$ of the sample and $39.1 \%$ watched TV for two or more hours every weekday.

SSBs were consumed 1 to 6 times a week by $29.5 \%$ of the sample and $31.2 \%$ at least once a day. ASBs were consumed 1 to 6 times a week by $24.5 \%$ and $39.4 \%$ at least once a day. The mean BMI in the sample at age 11 years was $19.1 \mathrm{~kg} / \mathrm{m}^{2}$ with $11.0 \%$ of children classified as overweight and
$18.9 \%$ as obese using internationally accepted cutpoints for children [23]. Mean percentage body fat was $20.1 \%$ (standard deviation 7.2) among boys and $24.6 \%$ (7.1) among girls.

\section{Correlates of weekly sweetened beverage consumption}

Correlates of weekly SSB and ASB consumption are shown in Table 2. Boys were more likely to drink SSBs than girls (62.3 \% vs. $59.1 \%$ ), and South Asian children were more likely to consume SSBs than White children (78.8 \% vs. $58.4 \%$ ). Children in families below $60 \%$ of the OECD median income were more likely to drink SSBs (73.8 \% vs. $57.4 \%)$ and there was indication of an inverse relationship with maternal qualifications (e.g. $73.9 \%$ among mothers with no formal qualifications vs. $52.5 \%$ among those with a university qualification). Children eating breakfast every day and those eating three or more portions of fruit per day were less likely to drink SSBs (e.g. $63.8 \%$ among those eating less than three portions of fruit vs. $56.5 \%$ among those eating three or more). Children watching two or more hours of TV on a weekday were more likely to consume SSBs (64.9\% vs. $58.1 \%)$.

South Asian and black children were less likely to drink ASBs than White children (51.7\%, $44.0 \%$ vs. $66.3 \%$ respectively). Children of mothers with a university qualification were less likely to drink ASBs than those with no formal qualifications (50.3 \% vs. $65.9 \%$ ). Children eating breakfast every day and those eating three or more portions of fruit per day were less likely to drink ASBs (e.g. $62.5 \%$ among those eating breakfast every day vs. $70.8 \%$ among those not eating breakfast every day). Children watching TV for two or more hours on weekdays were more likely to drink ASBs (67.1\% vs. $61.4 \%)$.

\section{Sweetened beverage consumption and adiposity}

Associations between SSB consumption and adiposity are shown in Table 3. In fully adjusted longitudinal analyses weekly $\left(+0.20 \mathrm{~kg} / \mathrm{m}^{2}, 0.10\right.$ to 0.31$)$ and daily $\left(+0.22 \mathrm{~kg} / \mathrm{m}^{2}, 0.11\right.$ to 0.34$)$ consumption of SSBs was associated with greater increases in BMI between the ages of 7 and 11 years. Both weekly $(+0.45 \%, 0.21$ to $0.69)$ and daily (+0.57\%, 0.30 to 0.83$)$ consumption of SSBs was associated with greater increases in percentage body fat between the ages of 7 and 11 years in fully adjusted longitudinal analyses. In fully adjusted cross sectional analyses both weekly $(+0.37 \%$, 0.05 to 0.70$)$ and daily $(+0.54 \%, 0.17$ to 0.92$)$ consumption of SSBs was associated with increased percentage body fat at age 11 years.

Associations between ASB consumption and adiposity are shown in Table 4 and Fig. 1. In fully adjusted longitudinal analyses daily ASB consumption $\left(+0.17 \mathrm{~kg} / \mathrm{m}^{2}, 0.06\right.$ 
Table 1 Characteristics of sample at age 11 years

\begin{tabular}{|c|c|c|}
\hline & & $N=13,170$ \\
\hline $\operatorname{Sex}(\%)$ & Girls & 49.5 \\
\hline \multirow[t]{4}{*}{ Ethnic group (\%) } & White & 82.9 \\
\hline & South Asian & 9.6 \\
\hline & African & 3.2 \\
\hline & Missing & 4.3 \\
\hline Equivalised income (\%) & Below $60 \%$ median & 20.7 \\
\hline \multirow{4}{*}{$\begin{array}{l}\text { Maternal educational } \\
\text { qualifications (\%) }\end{array}$} & No formal education & 15.1 \\
\hline & GCSE (taken at age 16) & 41.4 \\
\hline & $\begin{array}{l}\text { A-level or Diploma } \\
\text { (taken at age 18) }\end{array}$ & 24.5 \\
\hline & University & 19.0 \\
\hline \multirow[t]{4}{*}{ Country (\%) } & England & 64.8 \\
\hline & Wales & 14.1 \\
\hline & Scotland & 11.2 \\
\hline & Northern Ireland & 9.9 \\
\hline Fruit intake (\%) & $\geq 3$ portions per day & 41.7 \\
\hline Eats breakfast (\%) & $\begin{array}{l}\text { Eats breakfast } 7 \\
\text { days a week }\end{array}$ & 86.6 \\
\hline Diet at age 7 years (\%) & $\begin{array}{l}\text { On controlled diet } \\
\text { to lose weight }\end{array}$ & 5.1 \\
\hline \multirow{4}{*}{$\begin{array}{l}\text { Snacking between meals } \\
\text { (crisps, sweets and chocolate, } \\
\text { cakes and biscuits) at age } 7 \text { years (\%) }\end{array}$} & None & 19.6 \\
\hline & One & 38.3 \\
\hline & Two & 30.2 \\
\hline & Three & 11.9 \\
\hline \multirow[t]{3}{*}{ Sporting physical activity (\%) } & $\begin{array}{l}\text { Less than once per } \\
\text { week }\end{array}$ & 25.9 \\
\hline & 1-2 days per week & 42.0 \\
\hline & $\geq 3$ days per week & 32.1 \\
\hline Daily TV watching (\%) & $\geq 2 \mathrm{~h}$ & 39.1 \\
\hline Mode of travel to school (\%) & $\begin{array}{l}\text { Walk, cycle or } \\
\text { use bus }\end{array}$ & 58.7 \\
\hline \multirow[t]{3}{*}{ SSB consumption (\%) } & $<$ once a week/never & 39.3 \\
\hline & 1 - 6 days a week & 29.5 \\
\hline & At least once a day & 31.2 \\
\hline \multirow[t]{3}{*}{ ASB consumption (\%) } & <once a week/never & 36.4 \\
\hline & 1 - 6 days a week & 24.2 \\
\hline & At least once a day & 39.4 \\
\hline BMI (SD) & Mean & $19.1(3.4)$ \\
\hline \multirow[t]{3}{*}{ Weight status by BMI (\%) } & Normal weight & 70.1 \\
\hline & Overweight & 11.0 \\
\hline & Obese & 18.9 \\
\hline
\end{tabular}

Table 1 Characteristics of sample at age 11 years (Continued)

\begin{tabular}{|c|c|c|}
\hline \multirow[t]{2}{*}{$\%$ Body fat (SD) } & Boys & $20.1(7.2)$ \\
\hline & Girls & $24.6(7.1)$ \\
\hline Change in BMI age 7 to 11 years & Mean & $+2.6(2.1)$ \\
\hline $\begin{array}{l}\text { Change in } \% \text { body fat } \\
\text { age } 7 \text { to } 11 \text { years }\end{array}$ & Mean & $+1.3(4.9)$ \\
\hline
\end{tabular}

to 0.28) was associated with greater increases in BMI between the ages of 7 and 11 years. Daily ASB consumption was associated with greater increases in percentage body fat $(+0.35 \%, 0.09$ to 0.61$)$ between 7 and 11 years in fully adjusted analyses. In fully adjusted cross sectional analyses both weekly $\left(+0.47 \mathrm{~kg} / \mathrm{m}^{2}, 0.29\right.$ to 0.66$)$ and daily $\left(+0.58 \mathrm{~kg} / \mathrm{m}^{2}\right.$, 0.42 to 0.74 ) ASB consumption was associated with increased BMI at age 11 years. Weekly $(+0.88 \%, 0.49$ to 1.27$)$ and daily (+1.18 \%, 0.81 to 1.54$)$ ASB consumption were associated with an increased percentage body fat at 11 years.

\section{Sensitivity analyses}

Analyses using BMI Z-scores as our outcome measure produced similar results (Appendix Table 5). Analyses of percentage body fat adjusting for both height and height squared were also similar to main analyses (Appendix Table 6). Analyses using an exposure variable with separate categories for weekly ASB and SSB consumption produced findings which were consistent with those from our main analyses (Appendix Table 7). Analyses after excluding children who were obese at age 11 (Appendix Table 8) found attenuated associations between artificially sweetened beverage consumption and adiposity, although these remained statistically significant.

\section{Discussion}

This study used data from the UK Millennium Cohort Study to examine associations between SSB and ASB consumption and adiposity changes in UK children between 7 and 11 years. This age period is important as it is associated with accelerated weight gain [24]. We found that regular consumption of SSBs and ASBs was associated with greater increases in BMI and percentage body fat. These results remained statistically significant after adjusting for a variety of sociodemographic and behavioral factors associated with an increased risk of adiposity. ASB and SSB consumption was lower among children of mothers with higher educational qualifications and SSB consumption was higher 
Table 2 Correlates of weekly sugar and artificially sweetened beverage consumption at age 11 years

\begin{tabular}{|c|c|c|c|c|c|c|c|}
\hline & & $\%$ drinking SSB & $\mathrm{AOR}$ & $95 \% \mathrm{Cl}$ & $\%$ drinking ASB & $\mathrm{AOR}$ & $95 \% \mathrm{Cl}$ \\
\hline \multirow[t]{2}{*}{ Sex } & Boys & 62.3 & ref & ref & 64.2 & ref & ref \\
\hline & Girls & 59.1 & 0.86 & $0.79 ; 0.95$ & 63.0 & 0.97 & $0.88 ; 1.07$ \\
\hline \multirow[t]{3}{*}{ Ethnic group } & White & 58.4 & ref & ref & 66.3 & ref & ref \\
\hline & South Asian & 78.8 & 2.10 & $1.73 ; 2.56$ & 51.7 & 0.58 & $0.47 ; 0.71$ \\
\hline & Black & 62.8 & 0.96 & $0.72 ; 1.28$ & 44.0 & 0.42 & $0.29 ; 0.59$ \\
\hline \multirow[t]{2}{*}{ Income } & Normal & 57.4 & ref & ref & 63.4 & ref & ref \\
\hline & $<60 \%$ OECD median & 73.8 & 1.32 & $1.15 ; 1.5$ & 64.5 & 0.99 & $0.86 ; 1.15$ \\
\hline \multirow[t]{4}{*}{ Mothers' level of education } & No formal education & 73.9 & ref & ref & 65.9 & ref & ref \\
\hline & GCSE & 61.3 & 0.78 & $0.66 ; 0.93$ & 70.3 & 1.06 & $0.89 ; 1.26$ \\
\hline & A-level or Diploma & 56.5 & 0.71 & $0.59 ; 0.85$ & 62.7 & 0.78 & $0.65 ; 0.93$ \\
\hline & University & 52.5 & 0.64 & $0.52 ; 0.77$ & 50.3 & 0.47 & $0.38 ; 0.57$ \\
\hline \multirow[t]{4}{*}{ Country } & England & 62.0 & ref & ref & 60.5 & ref & ref \\
\hline & Wales & 58.9 & 1.00 & $0.87 ; 1.15$ & 72.2 & 1.32 & $1.15 ; 1.52$ \\
\hline & Scotland & 57.5 & 0.98 & $0.85 ; 1.13$ & 63.0 & 1.12 & $0.93 ; 1.34$ \\
\hline & Northern Ireland & 59.2 & 1.07 & $0.91 ; 1.27$ & 68.7 & 1.23 & $1.04 ; 1.45$ \\
\hline \multirow{2}{*}{$\begin{array}{l}\text { Portions of fruit eaten } \\
\text { per day }\end{array}$} & $<3$ & 63.8 & ref & ref & 65.8 & ref & ref \\
\hline & $\geq 3$ & 56.5 & 0.83 & $0.75 ; 0.92$ & 60.5 & 0.84 & $0.76 ; 0.93$ \\
\hline \multirow[t]{2}{*}{ Breakfast consumption } & Eats breakfast $<7$ days per week & 71.2 & ref & ref & 70.8 & ref & ref \\
\hline & Eats breakfast 7 days per week & 59.1 & 0.58 & $0.51 ; 0.67$ & 62.5 & 0.87 & $0.75 ; 1.01$ \\
\hline \multirow[t]{3}{*}{ Days per week active } & Less than once per week & 64.8 & ref & ref & 63.8 & ref & ref \\
\hline & 1-2 days per week & 60.3 & 0.94 & $0.83 ; 1.06$ & 64.8 & 1.00 & $0.88 ; 1.12$ \\
\hline & $\geq 3$ days per week & 58.1 & 1.04 & $0.92 ; 1.17$ & 61.9 & 0.93 & $0.8 ; 1.07$ \\
\hline \multirow{2}{*}{$\begin{array}{l}\text { Hours per weekday } \\
\text { spent watching TV }\end{array}$} & $<2 \mathrm{~h}$ & 58.1 & ref & ref & 61.4 & ref & ref \\
\hline & $\geq 2 \mathrm{~h}$ & 64.9 & 1.25 & $1.14 ; 1.37$ & 67.1 & 1.18 & $1.07 ; 1.31$ \\
\hline \multirow[t]{2}{*}{ Travel to school } & By car & 58.5 & ref & ref & 62.2 & ref & ref \\
\hline & By active travel & 62.3 & 1.11 & $1.01 ; 1.22$ & 64.7 & 1.14 & $1.04 ; 1.25$ \\
\hline
\end{tabular}

Weekly consumption = 1-6 days per week. SSB - Sugar-sweetened beverages, ASB - Artificially-sweetened beverages, AOR - Adjusted Odds Ratio, CI - Confidence intervals, OECD - Organization for Economic Co-operation and Development

among south Asian children. Children who did not eat breakfast every day and those watching more than two hours of TV per day were more likely to drink both ASBs and SSBs.

While SSB consumption is an established risk factor for adiposity [1], few studies have examined associations with ASBs. A regional study of 1200 children in England found a positive association between ASB consumption and changes in adiposity between 5 and 9 years [25]. However, the authors suggest that this finding may reflect reverse causality due to overweight children switching to ASBs as part of an unsuccessful weight loss strategy. Associations between ASB consumption and adiposity remained statistically significant in our sensitivity analysis which excluded children who were obese at age 11 years. This suggests that our findings are not fully explained by substitution to ASBs among heavier children. Our findings are also consistent with those from an intervention trial which found that substitution of SSBs with water resulted in substantially lower calorie intake when compared with substitution with ASBs [26] while an intervention directed at adolescents encouraging substitution to ASBs was not associated with lower BMI than controls [27]. These latter findings support the conclusion that in the absence of energy restrictions, switching to ASBs is not an effective strategy for weight loss [28].

A variety of possible mechanisms by which artificial sweeteners may be linked to weight gain have been proposed: such sweeteners may increase appetite and lead to increased consumption, or they may train the palate to enjoy similar sweet foods, which may or may not be low calorie [28, 29]. Another possible explanation is that people may consciously overcompensate for these low calorie options and overindulge in other intakes [28, 29]. There is at present no conclusive evidence on these 
Table 3 Associations between sugar-sweetened beverage (SSB) consumption and adiposity measures

\begin{tabular}{|c|c|c|c|c|c|}
\hline & & $\begin{array}{l}\text { Unadjusted coefficient } \\
\text { at age } 11(95 \% \mathrm{Cl})\end{array}$ & $\begin{array}{l}\text { Adjusted coefficient } \\
\text { at age } 11(95 \% \mathrm{Cl})\end{array}$ & $\begin{array}{l}\text { Unadjusted coefficient } \\
\text { age } 7-11(95 \% \mathrm{Cl})\end{array}$ & $\begin{array}{l}\text { Adjusted coefficient } \\
\text { age } 7-11(95 \% \mathrm{Cl})\end{array}$ \\
\hline \multicolumn{6}{|l|}{ Body Mass Index } \\
\hline N & & 12,368 & 10,443 & 11,318 & 10,283 \\
\hline \multirow[t]{2}{*}{ SSB consumption ${ }^{a}$} & Weekly & $0.12(-0.03 ; 0.28)$ & $0.12(-0.03 ; 0.26)$ & $0.24(0.14 ; 0.34)$ & $0.20(0.10 ; 0.31)$ \\
\hline & Daily & $0.15(-0.03 ; 0.32)$ & $0.13(-0.04 ; 0.30)$ & $0.29(0.19 ; 0.40)$ & $0.22(0.11 ; 0.34)$ \\
\hline \multicolumn{6}{|l|}{ Percentage body fat } \\
\hline$N$ & & 12,370 & 10,231 & 10,844 & 9851 \\
\hline \multirow[t]{2}{*}{ SSB consumption ${ }^{a}$} & Weekly & $0.38(0.03 ; 0.74)$ & $0.37(0.05 ; 0.70)$ & $0.49(0.25 ; 0.73)$ & $0.45(0.21 ; 0.69)$ \\
\hline & Daily & $0.52(0.15 ; 0.89)$ & $0.54(0.17 ; 0.92)$ & $0.61(0.35 ; 0.86)$ & $0.57(0.30 ; 0.83)$ \\
\hline
\end{tabular}

${ }^{a}$ Reference group children consuming sugar sweetened beverages less than once a week/never

Weekly consumption $=1-6$ days a week, Daily consumption = once a day or more than once a day

$\mathrm{Cl}$ - Confidence intervals. Models adjusted for: age (in months), sex, ethnic group, equivalised income, mother's highest educational qualification, country, portions of fruit consumer per day, breakfast consumption, days per week of sport/exercise, hours spent watching TV per weekday, mode of transport to school, being on a controlled diet at age 7 and snacking at age 7 . Models of change in adiposity adjusted for adiposity at age 7

possible mechanisms, and the area remains an open area of research [10, 28]. In addition to adiposity, ASBs have also been linked to other health outcomes, such as incident diabetes in a recent meta-analysis [30].

This study is the first national longitudinal examination of associations between SSBs and ASBs and adiposity among pre-adolescent children. We used two objective measures of adiposity in children and found similar associations for both which strengthens the findings. The MCS is designed to be representative of the population of the UK and the percentage of our sample which was overweight or obese is similar to officially published estimates. $29.9 \%$ of our sample was overweight or obese, which is similar to data from the National Child Measurement Programme for England which found $33.3 \%$ of age 10 and 11 year old children to be overweight or obese in 2012/13 [31]. Nonetheless, there are a number of study limitations that should be considered. Measurement of beverage consumption was based on caregiver reporting, as were potential confounding variables. The MCS is not specifically designed with a nutrition focus and it remains possible that there are other important elements of diet which we have not been able to control for. In particular, inclusion of data on overall diet quality would have been useful in exploration of these issues. However, there was no data available on overall diet quality, and the data we use on snacking behavior comes from age 7 and may not accurately reflect snacking at age 11.This means that residual confounding remains a possible explanation for these findings, especially given that adjustment reduced effect sizes. Nonetheless we did control for a wide range of factors related to adiposity in previous work.Our predictor variable was based on sweetened beverage consumption at age 11 years, rather than at both time points in the study. Inclusion of data on consumption from both time points would have allowed less cautious interpretation of the

Table 4 Associations between artificially sweetened beverage (ASB) consumption and adiposity measures

\begin{tabular}{|c|c|c|c|c|c|}
\hline & & $\begin{array}{l}\text { Unadjusted coefficient } \\
\text { at age } 11(95 \% \mathrm{Cl})\end{array}$ & $\begin{array}{l}\text { Adjusted coefficient } \\
\text { at age } 11(95 \% \mathrm{Cl})\end{array}$ & $\begin{array}{l}\text { Unadjusted coefficient } \\
\text { age } 7-11(95 \% \mathrm{Cl})\end{array}$ & $\begin{array}{l}\text { Adjusted coefficient } \\
\text { age 7-11 }(95 \% \mathrm{Cl})\end{array}$ \\
\hline \multicolumn{6}{|l|}{ Body Mass Index } \\
\hline$N$ & & 12,368 & 10,443 & 11,318 & 10,283 \\
\hline \multirow[t]{2}{*}{ ASB consumption ${ }^{a}$} & Weekly & $0.68(0.49 ; 0.87)$ & $0.47(0.29 ; 0.66)$ & $0.16(0.03 ; 0.29)$ & $0.14(0.00 ; 0.27)$ \\
\hline & Daily & $0.79(0.64 ; 0.94)$ & $0.58(0.42 ; 0.74)$ & $0.22(0.12 ; 0.32)$ & $0.17(0.06 ; 0.28)$ \\
\hline \multicolumn{6}{|l|}{ Percentage body fat } \\
\hline$N$ & & 12,370 & 10,231 & 10,844 & 9851 \\
\hline \multirow[t]{2}{*}{ ASB consumption ${ }^{a}$} & Weekly & $1.29(0.89 ; 1.70)$ & $0.88(0.49 ; 1.27)$ & $0.32(0.01 ; 0.63)$ & $0.26(-0.04 ; 0.55)$ \\
\hline & Daily & $1.48(1.12 ; 1.83)$ & $1.18(0.81 ; 1.54)$ & $0.39(0.15 ; 0.63)$ & $0.35(0.09 ; 0.61)$ \\
\hline
\end{tabular}

${ }^{\mathrm{a}}$ Reference group children consuming artificially sweetened beverages less than once a week/never Weekly consumption $=1-6$ days a week, Daily consumption = once a day or more than once a day

$\mathrm{Cl}$ - Confidence intervals. Adjusted models adjusted for: age (in months), sex, ethnic group, equivalised income, mother's highest educational qualification, country, portions of fruit consumer per day, breakfast consumption, days per week of sport/exercise, hours spent watching TV per weekday, mode of transport to school, being on a controlled diet at age 7 and snacking at age 7 . Models of change in adiposity adjusted for adiposity at age 7 


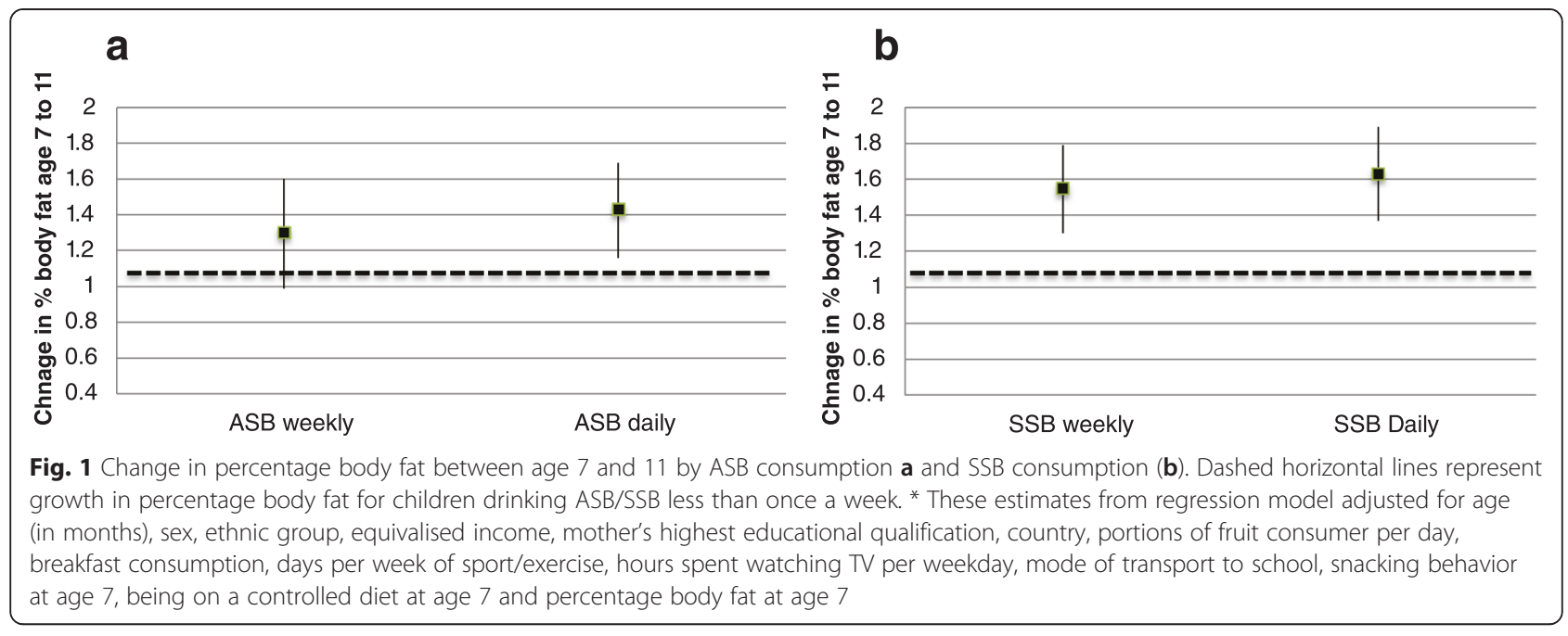

results presented here and without this further research is needed to determine potential associations between these beverages and adiposity in children. Although parents were asked about beverage consumption at age 7 years, the question referred only to intake between meals and did not discriminate between artificial and sugar sweetened beverages. We fitted a categorical variable for exposure to SSBs or ASBs which meant that there was some sweetened beverage consumption in the reference group (at most once a month). Exposure to ASBs and SSBs was not mutually exclusive in the sample as a large number of children $(40.7 \%)$ were consuming both. However, findings from sensitivity analysis which involved fitting a four way categorization where weekly SSB/ASB consumption was mutually exclusive were consistent with our main findings. Although changes in adiposity seen were modest and may be accounted for by measurement error at the individual level, given our sample size it is unlikely that our findings areentirely due to artefact. Our findings may be partly explained by reverse causality e.g. more adipose children switching to ASBs as part of an unsuccessful weight loss strategy. However, associations between ASB and adiposity were statistically significant in sensitivity analyses which excluded obese children.

The World Health Organization recently published draft guidance on sugar intake; that adults should keep their intake below $10 \%$ of total calories. The guidance also states that reducing sugar intake to below $5 \%$ of total calories would yield additional population health benefits [32]. The WHO guidance is underpinned by robust epidemiological evidence indicating sugar consumption as an important cause of excess weight gain in both adults and children globally $[1,33]$. Reducing SSB consumption offers considerable scope to achieve the WHO recommendations as SSBs account for up to $10 \%$ of children's energy intake in the UK [25]. Policy options to reduce intakes include upstream interventions such as cap and trade policies on adding sugar to the food chain, similar to the international carbon trading system [34]. Other proposed interventions include warning labels on SSBs [35], removing such drinks from schools [36] or additional taxes on such drinks (recently passed in Berkeley California). Findings from this and previous research indicate that encouraging substitution of SSBs with ASBs may not yield the health benefits originally intended in terms of adiposity or diabetes and substitution with water may be preferable Although evidence on policy impacts is emerging, the ubiquity of both SSBs and ASBs suggests that a variety of interventions are likely to be required in tandem, and that national governments will need support, co-ordination and guidance from international organizations [37]. Additionally, synergies identified between behaviors such as screen viewing and consumption [38], as well as the importance of physical activity [21] suggest that multi-faceted interventions tackling a variety of risk factors are likely to be be needed. Given our findings that consumption of sweetened beverages is higher in lower socioeconomic and ethnic minority groups, it is important that any impacts on inequalities in childhood obesity are carefully monitored.

\section{Conclusion}

This national longitudinal study found that both sugar and artificially sweetened beverage consumption was associated with increases in adiposity in pre-adolescent children. These findings strengthen a limited evidence base suggesting that artificially sweetened drinks may be contributing to, rather than constraining population level increases in adiposity. Obesity prevention strategies which aim to encourage substitution of SSBs with ASBs may not yield the benefits intended and this should be a focus for further research. 


\section{Appendix}

Table 5 Associations between sweetened beverage consumption and BMI Z-score

\begin{tabular}{|c|c|c|c|c|c|}
\hline & & $\begin{array}{l}\text { Unadjusted coefficient } \\
\text { at age } 11(95 \% \mathrm{Cl})\end{array}$ & $\begin{array}{l}\text { Adjusted coefficient } \\
\text { at age } 11(95 \% \mathrm{Cl})\end{array}$ & $\begin{array}{l}\text { Unadjusted coefficient } \\
\text { age } 7-11(95 \% \mathrm{Cl})\end{array}$ & $\begin{array}{l}\text { Adjusted coefficient } \\
\text { age } 7-11(95 \% \mathrm{Cl})\end{array}$ \\
\hline \multicolumn{6}{|l|}{ Sugar sweetened beverages } \\
\hline \multirow{2}{*}{$\begin{array}{l}\text { Sugar sweetened beverage } \\
\text { consumption at age } 11^{a}\end{array}$} & At least once a week & $0.04(0.00 ; 0.10)$ & $0.04(0.00 ; 0.09)$ & $0.08(0.04 ; 0.12)$ & $0.07(0.02 ; 0.11)$ \\
\hline & At least daily & $0.05(0.00 ; 0.11)$ & $0.04(-0.02 ; 010)$ & $0.11(0.07 ; 0.14)$ & $0.08(0.04 ; 0.12)$ \\
\hline \multicolumn{6}{|l|}{ Artificially sweetened beverages } \\
\hline \multirow{2}{*}{$\begin{array}{l}\text { Artificially sweetened beverage } \\
\text { consumption at age } 11^{\text {b }}\end{array}$} & At least once a week & $0.23(0.16 ; 0.29)$ & $0.17(0.10 ; 0.24)$ & $0.05(0.01 ; 0.10)$ & $0.04(-0.01 ; 0.10)$ \\
\hline & At least daily & $0.25(0.19 ; 0.30)$ & $0.19(0.12 ; 0.25)$ & $0.05(0.01 ; 0.09)$ & $0.04(0.01 ; 0.08)$ \\
\hline
\end{tabular}

${ }^{a}$ Reference group children consuming sugar sweetened beverages less than once a week/never

${ }^{b}$ Reference group children consuming artificially sweetened beverages less than once a week/never

Weekly consumption $=1-6$ days a week, Daily consumption = once a day/ more than once a day

$\mathrm{Cl}$ - Confidence intervals. Adjusted models adjusted for: ethnic group, equivalised income, mother's highest educational qualification, country, portions of fruit consumer per day, breakfast consumption, days per week of sport/exercise, hours spent watching TV per weekday and mode of transport to school, being on a controlled diet at age 7 , snacking at age 7 , and height squared. Models of change in adiposity adjusted for adiposity at age 7

Table 6 Associations between sweetened beverage consumption and percentage body fat, analyses including adjustment for height and height squared

\begin{tabular}{|c|c|c|c|c|c|}
\hline & & $\begin{array}{l}\text { Unadjusted coefficient } \\
\text { at age } 11(95 \% \mathrm{Cl})\end{array}$ & $\begin{array}{l}\text { Adjusted coefficient } \\
\text { at age } 11(95 \% \mathrm{Cl})\end{array}$ & $\begin{array}{l}\text { Unadjusted coefficient } \\
\text { age } 7-11(95 \% \mathrm{Cl})\end{array}$ & $\begin{array}{l}\text { Adjusted coefficient } \\
\text { age } 7-11(95 \% \mathrm{Cl})\end{array}$ \\
\hline \multicolumn{6}{|l|}{ Sugar sweetened beverages } \\
\hline \multirow{2}{*}{$\begin{array}{l}\text { Sugar sweetened beverage } \\
\text { consumption at age } 11^{a}\end{array}$} & Weekly & $0.34(0.00 ; 0.68)$ & $0.31(-0.01 ; 0.64)$ & $0.48(0.24 ; 0.73)$ & $0.42(0.18 ; 0.67)$ \\
\hline & Daily & $0.57(0.20 ; 0.94)$ & $0.52(0.15 ; 0.88)$ & $0.61(0.35 ; 0.86)$ & $0.54(0.28 ; 0.80)$ \\
\hline \multicolumn{6}{|l|}{ Artificially sweetened beverages } \\
\hline \multirow{2}{*}{$\begin{array}{l}\text { Artificially sweetened beverage } \\
\text { consumption at age } 11^{\mathrm{b}}\end{array}$} & Weekly & $1.20(0.80 ; 1.61)$ & $0.78(0.39 ; 1.17)$ & $0.36(0.05 ; 0.67)$ & $0.26(-0.03 ; 0.56)$ \\
\hline & Daily & $1.39(1.03 ; 1.74)$ & $1.04(0.69 ; 1.39)$ & $0.40(0.16 ; 0.64)$ & $0.33(0.08 ; 0.59)$ \\
\hline
\end{tabular}

${ }^{a}$ Reference group children consuming sugar sweetened beverages less than once a week/never

${ }^{\mathrm{b}}$ Reference group children consuming artificially sweetened beverages less than once a week/never

Weekly consumption $=1-6$ days a week, Daily consumption = once a day/more than once a day

$\mathrm{Cl}$ - Confidence intervals. Adjusted models adjusted for: age (in months), sex, ethnic group, equivalised income, mother's highest educational qualification, country, portions of fruit consumer per day, breakfast consumption, days per week of sport/exercise, hours spent watching TV per weekday and mode of transport to school, being on a controlled diet at age7and snacking at age 7. Models of change in adiposity adjusted for adiposity at age 7 
Table 7 Associations between weekly sugar-sweetened beverage consumption and adiposity measures

\begin{tabular}{|c|c|c|c|c|}
\hline & $\begin{array}{l}\text { Unadjusted coefficient } \\
\text { for adiposity at age } 11 \\
(95 \% \mathrm{Cl})\end{array}$ & $\begin{array}{l}\text { Adjusted coefficient } \\
\text { for adiposity at } \\
\text { age } 11(95 \% \mathrm{Cl})\end{array}$ & $\begin{array}{l}\text { Unadjusted coefficient } \\
\text { for change in adiposity } \\
\text { between } 7 \text { and } 11(95 \% \mathrm{Cl})\end{array}$ & $\begin{array}{l}\text { Adjusted coefficient } \\
\text { for change in adiposity } \\
\text { between } 7 \text { and } 11 \text { (95\% Cl) }\end{array}$ \\
\hline Category (\% of sample) & Body Mass Index & & & \\
\hline Neither (16.4 \%) & ref & ref & ref & ref \\
\hline ASB but not SSB (22.8\%) & $0.91(0.70 ; 1.12)$ & $0.72(0.50 ; 0.95)$ & $0.20(0.06 ; 0.34)$ & $0.13(-0.01 ; 0.26)$ \\
\hline SSB but not ASB (20.0\%) & $0.24(0.02 ; 0.46)$ & $0.17(-0.05 ; 0.39)$ & $0.28(0.13 ; 0.42)$ & $0.20(0.06 ; 0.34)$ \\
\hline Both (40.8\%) & $0.86(0.69 ; 1.04)$ & $0.65(0.45 ; 0.86)$ & $0.44(0.31 ; 0.56)$ & $0.33(0.19 ; 0.47)$ \\
\hline Category (\% of sample) & Percentage body fat & & & \\
\hline Neither (16.8 \%) & ref & ref & ref & ref \\
\hline ASB but not SSB (23.5\%) & $1.60(1.10 ; 2.11)$ & $1.39(0.86 ; 1.92)$ & $0.25(-0.10 ; 0.61)$ & $0.22(-0.13 ; 0.60)$ \\
\hline SSB but not ASB (19.0\%) & $0.57(0.07 ; 1.08)$ & $0.54(0.05 ; 1.05)$ & $0.46(0.10 ; 0.82)$ & $0.47(0.10 ; 0.84)$ \\
\hline Both (40.7\%) & $1.78(1.38 ; 2.19)$ & $1.49(1.05 ; 1.94)$ & $0.82(0.51 ; 1.12)$ & $0.73(0.41 ; 1.05)$ \\
\hline
\end{tabular}

Weekly consumption $=$ at least one day per week

ASB - artificially sweetened beverages, SSB - sugar sweetened beverages, $\mathrm{Cl}$ - Confidence intervals

Adjusted models adjusted for: age (in months), sex, ethnic group, equivalised income, mother's highest educational qualification, country, portions of fruit consumer per day, breakfast consumption, days per week of sport/exercise, hours spent watching TV per weekday and mode of transport to school, being on a controlled diet at age 7 and snacking at age 7 . Models of change in adiposity adjusted for adiposity at age 7

Table 8 Associations between sweetened beverage consumption and adiposity measures, excluding children obese at age 11

\begin{tabular}{|c|c|c|c|c|c|}
\hline & & $\begin{array}{l}\text { Unadjusted coefficient } \\
\text { at age } 11(95 \% \mathrm{Cl})\end{array}$ & $\begin{array}{l}\text { Adjusted coefficient } \\
\text { at age } 11(95 \% \mathrm{Cl})\end{array}$ & $\begin{array}{l}\text { Unadjusted coefficient } \\
\text { age } 7-11(95 \% \mathrm{Cl})\end{array}$ & $\begin{array}{l}\text { Adjusted coefficient } \\
\text { age } 7-11(95 \% \mathrm{Cl})\end{array}$ \\
\hline \multicolumn{6}{|l|}{ Body Mass Index } \\
\hline \multirow{2}{*}{$\begin{array}{l}\text { Artificially sweetened beverage } \\
\text { consumption at age } 11^{\mathrm{a}}\end{array}$} & Weekly & $0.28(0.15 ; 0.40)$ & $0.32(0.18 ; 0.45)$ & $0.12(0.02 ; 0.22)$ & $0.12 ; 0.01 ; 0.22)$ \\
\hline & Daily & $0.30(0.19 ; 0.42)$ & $0.31(0.18 ; 0.44)$ & $0.13(0.04 ; 0.22)$ & $0.13(0.03 ; 0.23)$ \\
\hline \multicolumn{6}{|l|}{ Percentage body fat } \\
\hline \multirow{2}{*}{$\begin{array}{l}\text { Artificially sweetened beverage } \\
\text { consumption at age } 11^{\mathrm{a}}\end{array}$} & Weekly & $0.43(0.05 ; 0.28)$ & $0.47(0.38 ; 0.62)$ & $0.17(0.05 ; 0.28)$ & $0.18(0.05 ; 0.30)$ \\
\hline & Daily & $0.38(0.26 ; 0.50)$ & $0.36(0.23 ; 0.50)$ & $0.16(0.07 ; 0.26)$ & $0.15(0.06 ; 0.25)$ \\
\hline
\end{tabular}

${ }^{a}$ Reference group children consuming artificially sweetened beverages less than once a week/never

Weekly consumption =1-6 days a week, Daily consumption = once a day/ more than once a day

Adjusted models adjusted for: age (in months), sex, ethnic group, equivalised income, mother's highest educational qualification, country, portions of fruit consumer per day, breakfast consumption, days per week of sport/exercise, hours spent watching TV per weekday and mode of transport to school, being on a controlled diet at age 7 and snacking at age 7 . Models of change in adiposity adjusted for adiposity at age 7 


\section{Competing interests}

The authors declare that they have no competing interests.

\section{Authors' contributions}

$A L$ and $L M$ cleaned and analyzed the data. $A L, C M$ and $L M$ designed the study and conceived of the study questions. AL wrote the first draft of the manuscript and all authors gave significant intellectual input to its redrafting, and approved the final version for submission.

\section{Author details}

${ }^{1}$ Department of Primary Care and Public Health, School of Public Health, Imperial College London, Reynolds Building, St Dunstan's Road, London W6 8RP, United Kingdom. ²Departamento de Nutrição, Faculdade de Saúde Pública, Universidade de São Paulo, São Paulo, Brazil.

Received: 15 May 2015 Accepted: 22 October 2015

Published online: 26 October 2015

\section{References}

1. Morenga LT, Mallard S, Mann J. Dietary sugars and body weight: systematic review and meta-analyses of randomised controlled trials and cohort studies. BMJ. 2013;346.

2. Basu S, McKee M, Galea G, Stuckler D. Relationship of Soft Drink Consumption to Global Overweight, Obesity, and Diabetes: A Cross-National Analysis of 75 Countries. Am J Public Health. 2013;103(11):2071-7.

3. Malik VS, Popkin BM, Bray GA, Després J-P, Willett WC, Hu FB. SugarSweetened Beverages and Risk of Metabolic Syndrome and Type 2 Diabetes: A meta-analysis. Diabetes Care. 2010;33(11):2477-83.

4. Mekonnen TA, Odden MC, Coxson PG, et al. Health benefits of reducing sugar-sweetened beverage intake in high risk populations of California: results from the cardiovascular disease (CVD) policy model. PLoS One. 2013;8(12), e81723

5. Cradock AL, McHugh A, Mont-Ferguson H, et al. Effect of school district policy change on consumption of sugar-sweetened beverages among high school students, Boston, Massachusetts, 2004-2006. Prev Chronic Dis. 2011;8(4):A7

6. Royal College of Physicians Ireland (2014). The race we don't want to win: Tackling Ireland's obesity epidemic. http://www.rcpi.ie/content/docs/ 000001/2051_5_media.pdf?1409562906.

7. Kleiman S, Ng SW, Popkin B. Drinking to our health: Can beverage companies cut calories while maintaining profits? Obes rev : an official journal of the International Association for the Study of Obesity. 2012;13(3):258-74.

8. Kit BK, Fakhouri TH, Park S, Nielsen SJ, Ogden CL. Trends in sugarsweetened beverage consumption among youth and adults in the United States: 1999-2010. Am J Clin Nutr. 2013;98(1):180-8.

9. Suez J, Korem T, Zeevi D, et al. Artificial sweeteners induce glucose intolerance by altering the gut microbiota. Nature. 2014;514(7521):181-6.

10. Brown RJ, De Banate MA, Rother Kl. Artificial Sweeteners: A systematic review of metabolic effects in youth. Int j pediatr obes : IJPO : an official journal of the International Association for the Study of Obesity. 2010;5(4):305-12

11. O'Connor TM, Yang S-J, Nicklas TA. Beverage Intake Among Preschool Children and Its Effect on Weight Status. Pediatrics. 2006;118(4):e1010-8.

12. University of London. Institute of Education. Centre for Longitudinal Studies, Millennium Cohort Study: Fifth Survey, 2012 [computer file]. Colchester, Essex: UK Data Archive [distributor], February 2014. SN: 7464, http://dx.doi.org/10.5255/UKDA-SN-7464-1.

13. Connelly R, Platt L. Cohort Profile: UK Millennium Cohort Study (MCS). Int Epidemiol. 2014;43(6):1719-25.

14. Brophy S, Cooksey R, Gravenor MB, et al. Risk factors for childhood obesity at age 5: Analysis of the Millennium Cohort Study. BMC Public Health. 2009;9.

15. Carlson JA, Crespo NC, Sallis JF, Patterson RE, Elder JP. Dietary-Related and Physical Activity-Related Predictors of Obesity in Children: A 2-Year Prospective Study. Child Obes. 2012;8(2):110-5.

16. Hills AP, Andersen LB, Byrne NM. Physical activity and obesity in children. Br J Sports Med. 2011;45(11):866-70.

17. Organisation for Economic Cooperation and Development (2011).Society at a glance: OECD social indicators http://www.oecd.org/berlin/47570121.pdf.
18. Mostafa T. Millennium Cohort Study. Technical report on response in sweep 5 (age 11). http://eprints.ioe.ac.uk/18759/1/Technical_Report_on_ Response_in_Sweep5_for_web_TM.pdf 2014.

19. Cole TJ. The LMS, method for constructing normalized growth standards. Eur J Clin Nutr. 1990;44(1):45-60.

20. Bigornia SJ, LaValley MP, Noel SE, Moore LL, Ness AR, Newby PK. Sugarsweetened beverage consumption and central and total adiposity in older children: a prospective study accounting for dietary reporting errors. Public Health Nutr. 2014;1-9.

21. Ness AR, Leary SD, Mattocks C, et al. Objectively Measured Physical Activity and Fat Mass in a Large Cohort of Children. PLoS Med. 2007;4(3), e97.

22. McCarthy HD, Cole TJ, Fry T, Jebb SA, Prentice AM. Body fat reference curves for children. Int J Obes (Lond). 2006;30(4):598-602.

23. Cole TJ, Bellizzi MC, Flegal KM, Dietz WH. Establishing a standard definition for child overweight and obesity worldwide: international survey BMJ. 2000;320:1240-1243.; 2000.

24. Institute of education (2014). Briefing paper. Child overweight and obesity: Initial findings from the Millennium Cohort Study Age 11 survey. http://www.cls.ioe.ac.uk/page.aspx?\&sitesectionid=1330\&sitesectiontitle=MCS +age+11+initial+findings.

25. Johnson L1, Mander AP, Jones LR, Emmett PM, Jebb SA. Is sugar-sweetened beverage consumption associated with increased fatness in children? Nutrition. 2007;23(7-8):557-63.

26. Stookey JD, Constant F, Gardner CD, Popkin BM. Replacing Sweetened Caloric Beverages with Drinking Water Is Associated with Lower Energy Intake. Obesity. 2007;15(12):3013-22.

27. Ebbeling CB, Feldman HA, Osganian SK, Chomitz VR, Ellenbogen SJ, Ludwig DS. Effects of Decreasing Sugar-Sweetened Beverage Consumption on Body Weight in Adolescents: A Randomized. Controlled Pilot Study Pediatrics. 2006;117(3):673-80

28. Mattes RD, Popkin BM. Nonnutritive sweetener consumption in humans: effects on appetite and food intake and their putative mechanisms. Am J Clin Nutr. 2009;89(1):1-14.

29. Gardner C, Wylie-Rosett J, Gidding SS, et al. Nonnutritive Sweeteners: Current Use and Health Perspectives: A Scientific Statement From the American Heart Association and the American Diabetes Association. Circulation. 2012;126(4):509-19.

30. Greenwood DC, Threapleton DE, Evans CE, et al. Association between sugar-sweetened and artificially sweetened soft drinks and type 2 diabetes: systematic review and dose-response meta-analysis of prospective studies. Br J Nutr. 2014:112(5):725-34.

31. Health and Social Care Information Centre. National Child Measurement Programme: England, 2012/13 school year. http://www.hscic.gov.uk/ catalogue/PUB13115/nati-chil-meas-prog-eng-2012-2013-rep.pdf 2013.

32. Gulland A. Average daily consumption of sugar must be halved, says WHO. 2014:348:92003

33. Malik VS, Pan A Fau - Willett WC, Willett WC Fau - Hu FB, Hu FB. Sugarsweetened beverages and weight gain in children and adults: a systematic review and meta-analysis. American Journal of Clinical Nutrition 2013; (1938-3207 (Electronic)).

34. Basu S, Lewis K. Reducing Added Sugars in the Food Supply Through a Cap-and-Trade Approach. Am J Public Health. 2014;104(12):2432-8.

35. Capewell S. Sugar sweetened drinks should carry obesity warnings. BMJ. 2014;348:g3428.

36. Masse LC, de Niet-Fitzgerald JE, Watts AW, Naylor PJ, Saewyc EM. Associations between the school food environment, student consumption and body mass index of Canadian adolescents. Int J Behav Nutr Phy. 2014;11.

37. UK Health Forum (2014). Options for action to support the reduction of sugar intakes in the UK: A discussion paper produced by the UK Health Forum for Public Health England. http://bit.ly/UKHFsugar

38. Olafsdottir S, Berg C, Eiben G, et al. Young children/'s screen activities, sweet drink consumption and anthropometry: results from a prospective European study. Eur J Clin Nutr. 2014;68(2):223-8. 